\title{
Classroom Management in Pre-service Teachers' Teaching Practice Demo Lessons: A Comparison to Actual Lessons by In-service English Teachers
}

\author{
Perihan Korkut \\ Correspondence: English Language Teaching, Muğla Sıtkı Koçman University, Turkey. \\ Received: January 20, 2017 \\ doi:10.11114/jets.v5i4.2164 \\ Accepted: February 20, $2017 \quad$ Online Published: February 22, 2017 \\ URL: https://doi.org/10.11114/jets.v5i4.2164
}

\begin{abstract}
The pre-service teachers find the chance to practice their classroom management skills during their practicum as they present demo lessons under supervision of their university instructors and mentor teachers. It had been discovered in a previous study, however, that the interactional features during the classroom management episodes in pre-service teachers' demo lessons were different from those in the lessons of the in-service teachers. The aim of this study was to unveil how pre-service teachers manage their classes differently from in-service teachers by carrying out a fine-grained comparison. The point-by-point comparison revealed both qualitative and quantitative differences which might not be immediately obvious to an observer at first sight. The differences were discussed in terms of the specific procedures of the teaching practice course and some suggestions were presented.
\end{abstract}

Keywords: classroom management, teaching practice course, teacher education, pre-service and in-service teacher differences

\section{Introduction}

Even a very well-planned lesson can fail if the classroom is managed poorly. "Classroom management is the central element of every teacher's daily professional experience" (Wright, 2005, p.1). Albeit its importance, it is often taken for granted and it hardly goes beyond general, common sense do's and don'ts advice from experienced teachers (Martin, 2004; Brophy, 2006). This study was motivated by the realization of certain differences between the pedagogic goals and classroom interaction patterns during the managerial mode in the teaching practice demo lessons of senior ELT students (pre-service teachers hereafter) and the lessons of in-service ELT teachers (Korkut, 2015). Managerial mode is one of the four modes in the Self Evaluation Teacher Talk (SETT) framework and it can be described as episodes in a lesson when the teacher is managing the classroom (Walsh, 2006). Since Walsh's (2006) SETT framework accounts only for the interactional features in the classroom talk, the differences between the lessons of pre-service and in-service teachers in terms of managerial mode cannot elucidate all the aspects of classroom management. Nevertheless, mere existence of such differences calls for a more detailed investigation of the data from a wider perspective.

It is predictable that in-service and pre-service teachers will have different lessons thanks to stage theories that explain the development of classroom management skills by experience such as Berliner, Kagan, and Maynard and Furlong (as cited in Wright, 2005, p. 279). This study aims to find out these differences explicitly to enlighten the possible areas of attention for teacher training. As Kiely and Askham (2012) pointed out research has two functions; "first, it has the task of establishing, testing, and verifying theories of teaching and teacher learning which can inform curriculum practices in teacher education programmes, and second, it has to make sense of the range of practices within teacher education programmes and the intuitive knowledge base which underpins these" (p. 497). The findings of this research can be used for both of those functions; it can both help us understand how demo lessons are different from real English lessons and what affordances the teaching practice component at the education faculties can provide for more effective teacher training.

\subsection{The Teaching Practice Course}

The Teaching Practice course is placed on the last term of the 8-term programme in the ELT departments in Turkey. The students are appointed to state schools and they usually work with a mentor who is an English teacher there. Also a faculty member is appointed as the supervisor. Typically, the teaching practice course requires some observation tasks, which are carried out by observing the mentor's lessons, as well as some practice tasks in which the student prepares and makes a demo lesson with the mentor's class. This demo lesson can be observed and graded by the mentor, the 
supervisor, or both. The Teaching Practice is thus a chance for hands on experience whereby the pre-service teachers can try out their skills, engage in reflective practice, and receive feedback on their practices. The teaching practice course can be considered as critical since the process itself can be problematic in many ways (Hobson, Ashby, Malderez \& Tomlinson, 2009; Merç \& Subaş1, 2015; Macias \& Sanches, 2015) and it can have an effect on the pre-service teachers' self-perceptions (Caires, Almeida \& Vieira, 2012; Cabaroğlu, 2012).

\subsection{Classroom Management}

In this study, the term classroom management is understood as "the management of classroom for learning" (Tsui, 2003, p.136). It includes not only aspects of classroom organization such as group-pair-and solo-work, maintaining an orderly and peaceful environment, and doing the routine business but also making arrangements to motivate and empower the learners. Similarly, Wright (2005) describes the core elements of classroom management as managing the space, the time, engagement and participation. Space and time set the boundaries of education. We can extend the time and space boundaries of a lesson with the help of internet and homework assignments. Engagement entails motivation, approaches to learning, attitudes, and previous experience. Managing space, time, and engagement usually go hand in hand. The classroom is a social discourse world. Whether to talk or not to talk, being on-task or off-task, relations with other people are within the interest domain of classroom management.

Scrivener (2005), who is the author of one of the most popular methodology books in the ELT departments in Turkey, takes a similar stance in the Classroom management chapter of his book. According to it, classroom management is discussed under the headings of "grouping and seating, activities, authority, critical moments such as the beginning and the end of the lesson, tools and techniques, and working with people" (p. 79). The grouping and seating part involves the importance of physical qualities in establishing a good learning environment. The activities part holds that the potential of an activity can be hindered by poor application no matter how well it has been planned beforehand. The teacher's authority is reflected in the teacher's gathering and holding attention, deciding who does what, and getting someone to do something. In addition, how the teacher manages the critical moments such as the beginning and the ending of lessons are considered within the domain of classroom management. There is also a part devoted to the use of tools such as the board, book, gestures and techniques such as using silence as a classroom management tool. The working with people part reminds us that classroom management is not confined to managing the physical classroom, the students' behaviours, and the activities. It also involves dealing with the students as persons. Scrivener includes such sub-topics as "spreading your attention evenly and appropriately, using intuition to gauge what students are feeling, eliciting honest feedback, and really listening to students" in this part (p.80).

Classroom Management was a taken-for-granted aspect of teaching until recently. There was not explicit research focus on classroom management until 1950s. It came from behaviourist and ecological research (Brophy, 2006). Behaviourist research focused on the acceptable and disrupting behaviour during the lessons and resulted in Assertive Discipline Program which still keeps its popularity. Ecological studies took a more general look at the classroom environment and dealt mainly with the questions like "What do effective managers do?" rather than looking at students' behaviour. One of the most important figures in this line of research was Kounin (Brophy, 2006). Brophy also belongs to process-outcome studies. They took an outcome oriented approach in defining good classroom management. Instead of having key variables as fixed rules, age and level are considered. For example, unpredictability is not as crucial in young learners because it is more important that everyone gets a turn.

When we look at contemporary research on the issue of classroom management in terms of pre-service teachers' experiences, we see that some focus on the problems in classroom management. For example, Ragawanti (2015) identified the classroom management problems of student teachers through their reflective journals. Using Scrievener's (2005) classification of classroom management, he found that the most problematic area was managing critical moments, especially in terms of maintaining the silence and controlling the noise level. Merç and Subaş1 (2015) investigated the problems of student teachers about classroom management and how they cope with these problems. They found that problems generally come from students, the teaching point and materials, and cooperating teachers. To cope with the problems they face, student teachers use their knowledge from methodology lessons, they consult to their cooperating teachers and they think about their experiences with their previous teachers. A very similar one conducted in Columbia is Macias and Sanches's (2015) study. They found that the challenges came from the physical characteristics of classrooms, pre-service teachers' perception of the students' behaviour, and the students' disruptive behaviours. They identified focus on maintaining control and focus on good students as coping strategies. Ilın (2014) investigated the perspectives of ELT student teachers about the practicum experience in general. Among other findings, she reported that the student teachers contradict with the mentors most in terms of classroom management. They criticized their mentors for not using classroom rules, scolding and threatening the students, teaching only to the interested ones, not being able to manage the time, ignoring students' reactions, not keeping their promises, and punishing the students. Ünal and Ünal (2012) compared the pre-service and in-service teachers' classroom management 
approaches and found that although the less experienced teachers begin their career with a more non-interventionist approach, they become interventionist as they gain experience.

Another line of research focused on the self-efficacy beliefs and perspectives of the pre-service teachers regarding classroom management. İnceçay and Keşli Dollar (2012) looked at the classroom management skills, self-efficacy and readiness levels of pre-service English teachers using scales and observational data. They found that although student teachers' self-efficacy and readiness levels were related, these were not related to what they actually did in their demo lessons. Moreover, in Cabaroğlu's (2012) study, their self-efficacy, confidence, and readiness levels changed in various ways after the teaching practice. Some students were affected from the experience positively while others had lower self-confidence and self-efficacy afterwards. In another study, a survey form is delivered to the pre-service teachers to investigate their use, confidence, and success in various classroom management strategies (Reupert \& Woodcock, 2010). According to the findings, the pre-service teachers were able to use low-level corrective strategies although they believed that preventive strategies are more successful strategies.

As seen, the research on the classroom management skills of pre-service teachers is mostly based on the pre-service teachers' own reflections and expressions. In contrast, this study relies on observation of the actual practices of pre-service and in-service teachers. Looking at the issue from a fresh angle can fill in a gap in the literature and provide a better grasp of the teaching practice demo lessons' utility. The answer to the research question "What are the differences between the lessons of in-service and pre-service teachers in terms of each subheading in Scrivener's (2005) model?" was sought. By answering this question, we can infer the most important things to focus on in our teacher training.

\section{Method}

\subsection{Research Design}

This is a descriptive study in which the lessons of pre-service and in-service English teachers are compared in terms of classroom management. A tallying system based on Scrivener's (2005) description was used to determine the frequency of occurrences which are related to classroom management. Once the frequencies are determined, they are compared and the similarities and differences are discussed by example extracts from the data. Transcription conventions are explained in Appendix A.

"Classroom management involves both decisions and actions. The actions are what is done in the classroom, e.g. re-arranging the chairs. The decisions are about whether to do these actions, when to do them, how to do them, who will do them, etc" (Scrivener, 2005, p.80). In this study, the options and choices were not considered since they are not immediately obvious for observation and as Scrivener says, it is not possible to compare the effectiveness of each option divorced from the details of the particular situation (p.80). What can be directly observed and readily obvious is the "actions" part. Therefore, the codes are created by thinking about the actions that can indicate that domain. For example, in the model, there is "spreading your attention evenly" principle. This is translated into observable actions that can be recorded into a tallying system. For example, whenever the teacher lets or does not let a student initiation to happen, a code was tallied. It was assumed that how the teacher distributes his/her attention among students can be traced by looking at how he/she responds when a student initiates a topic or asks for individual help. The complete tallying system can be found in Appendix B.

\subsection{Participants}

The data of this study was an extracted portion of a larger collection which had been collected for the researcher's $\mathrm{PhD}$ thesis. The larger data included 29 lessons from 19 participants. 10 of the participants were in-service English teachers working at the state schools in the city centre while the other 9 were seniors from the ELT department of State University located in that city who were taking their teaching practice lessons at the time of data collection. In-service teachers were recorded during 2 consecutive lessons in 2013. In 2014, pre-service teachers worked in pairs and designed a session comprised of 2 consecutive lessons. Each pre-service teacher was observed during one entire lesson. All the participants' active and passive consent were sought and the necessary permission was granted from the ministry of education before all the recording activities.

As the sample was extracted from the larger data, the researcher worked meticulously to achieve the best balance possible between the pre-service and in-service teacher groups. Since a frequency count would be the basis of all the findings, it was critical that the duration of the data and the characteristics of the lessons are similar. Albeit pre-service data was collected one year later than the in-service data, all the lessons were recorded in the same city and at the same schools. The researcher, who has past experience as teacher and supervisor in that city for more than 10 years, did her best in order to ensure that the chosen lessons are comparable in terms of the roles and responsibilities of the teacher and the students. The researcher picked the lessons in which the teacher is following the book since such lessons made 
up the bulk of the data. Then, the lessons with $8^{\text {th }}, 9^{\text {th }}$, and $10^{\text {th }}$ grade students were excluded because all pre-service teachers had their lessons only with younger learners. Then, the participants were picked so that both genders are represented equally.

Accordingly, the structure of the data that was used for this study is described in Table 1 below.

Table 1. The Structure of the Data

\begin{tabular}{lll}
\hline & Pre-service teachers & In-service teachers \\
No of participants & 8 seniors (4 pairs) & 4 teachers \\
Gender distribution of participants & 4 males and 4 females (50\%) & 2 males and 2 females $(50 \%)$ \\
No of recorded lessons & 8 (2 consecutive lessons per pair) & 8 (2 consecutive lessons per teacher) \\
Grade level of the recorded lessons & $4^{\text {th }}$ and $7^{\text {th }}$ grades & $5^{\text {th }}, 6^{\text {th }}$ and $7^{\text {th }}$ grades \\
Classroom activities & Exercises in the book & Exercises in the book \\
Duration of the recorded data & 336 minutes & 348 minutes \\
\hline
\end{tabular}

\subsection{Data Collection Tools and Procedures}

The data was collected via video recording device which included two cameras and a lapel microphone on the teacher's collar. As mentioned earlier, the necessary permissions were granted and the recording activities were scheduled beforehand. On the day of the recording, the teachers signed on a consent form informing them about the issues related to data analysis, data protection and anonymity. All the in-service teachers were given numbers such as T1, T2, etc; pre-service teachers, TR1, TR2, etc. The names of the students were not indicated where possible. Instead of their names $\mathrm{S}$ or SS were used. If a name is required in the transcription, pseudo-names were given to the students. In the direction of the teachers' and school principals' advice, the passive consent of the students was granted. Some blind spots for the camera were purposefully formed for the students who do not want to appear on the recordings. Also all students were informed orally before the day of recording.

\subsubsection{Validity and Reliability}

The researcher developed a tallying system based on Scrievener (2005). The system was shown to two specialists to ensure validity. After a consensus was reached, it was refined according to the expert views. After that, one of the experts analyzed a portion of the data using the codes. The inter-coder reliability was calculated according to "point by point method" (Tawney \& Gast, 1984). The number of agreements was divided by the number of agreements plus the number of disagreements and multiplied by 100 . Accordingly, the inter-coder reliability was calculated as 95,6.

\subsection{Data Analysis}

The data was analyzed by the researcher. All the transcripts were prepared in MS Word ' 07 format and codes were labelled using the insert comment function. The frequency counts were made via find function on the MS Word program. Further analyses were carried out by hand.

Each code was counted in the pre-service and the in-service teachers' data and the frequencies were compared. Since the number of participants is small, one participants' excessive use of a code might distort the frequencies easily. In order to overcome this limitation, always the numbers of tallies were provided along with percentages. Moreover, extra information about the tallies was also provided where necessary. In addition, further analyses were carried out whereby samples from the transcripts were examined from a discourse analytic stand point in order to determine the qualitative differences and similarities. The findings were presented as tables and discussed with sample extracts from the data in the Results section.

\section{Results}

\subsection{Overall Results}

A total of 2056 tallies were marked throughout the data. The distribution of these according to each category is given in Table 2 below.

Table 2. Distribution of codes according to data sets

\begin{tabular}{lllllll}
\hline & \multicolumn{2}{l}{ Pre- service teachers } & \multicolumn{2}{l}{ In service teachers } & Total \\
& $\mathbf{n}$ & $\mathbf{\%}$ & $\mathbf{n}$ & $\mathbf{\%}$ & $\mathbf{n}$ & $\mathbf{\%}$ \\
Grouping and Seating & 499 & 24 & 451 & 22 & 950 & 46 \\
Activities & 117 & 6 & 183 & 9 & 300 & 15 \\
Authority & 113 & 5 & 223 & 11 & 336 & 16 \\
Critical Moments & 11 & 1 & 20 & 1 & 31 & 2 \\
Tools and Techniques & 25 & 1 & 79 & 4 & 104 & 5 \\
Working with People & 128 & 6 & 197 & 10 & 325 & 16 \\
\hline
\end{tabular}

As shown in the table, grouping and seating decisions were coded 950 times (46\%). This category includes dealing with the physical classroom. For example, the teacher can move the place of a desk or a student, control the heat, light, 
noise levels to optimize the environment for learning, and use his or her physical presence purposefully by standing nearby a student, or taking an advantage position in the room to see all students. The second ranking was shared by two categories; Authority (16\%) and Working with people (16\%). These are times when the teacher is in a superior position according to the students. For example, when the teacher asks a student to do something, warns somebody not to do something, or when a student asks for permission. The teacher makes sure that everyone gets enough chances for participation. Students and the teacher have a history together, and the teacher can make use of shared memories to ensure a more positive learning environment. At the same time, classrooms are places where learning activities take place; the actions that the teacher takes with the purpose of conducting activities were coded under the Activities category and this was the third most frequent (15\%) category in the data. Critical Moments got the $2 \%$, and Tools and techniques category got the $5 \%$ of the tallies.

\subsection{Grouping and Seating}

In the Grouping and Seating category (Table 3), the bulk of the classroom management actions are tallied for 1C, the teacher's movement pattern (93\%). It was created because "deciding where you stand or sit" is included under the "grouping and seating category" in Scrivener's (2005) model. Each time the teacher changed his or her position in the classroom, a 1C was marked, resulting in many tallies. The other codes; $1 \mathrm{~A}$ and 1B, refer to arranging who will sit where, and creating the suitable physical conditions for learning, respectively. Table 3 shows the distribution of the tallies for each code.

Table 3. Grouping and Seating

\begin{tabular}{lllllll}
\hline & Pre-service & & In-service & \multicolumn{2}{c}{ Total } \\
& $\mathbf{n}$ & $\mathbf{\%}$ & $\mathbf{n}$ & $\mathbf{\%}$ & $\mathbf{n}$ & $\mathbf{\%}$ \\
Seating arrangement (1A) & 2 & 0 & 6 & 1 & 8 & 1 \\
Physical conditions (1B) & 15 & 2 & 43 & 4 & 58 & 6 \\
Movement pattern (1C) & 482 & 51 & 402 & 42 & 884 & 93 \\
\hline
\end{tabular}

If we look at the code $1 \mathrm{~A}$ (grouping and seating) in more detail, we see that the pre-service teachers did not deal with seating arrangement and physical conditions as many times as the in-service teachers. Only T3 did not have a tally for seating arrangement. All the other three in-service teachers shared the 6 tallies for the code 1A. T2 also changed the place of a desk. On the other hand, among the four pre-service teachers, only one pair (TR7 and TR8) changed the places of students because it was the requirement of the specific exercise they had been doing.

Table 4. Seating arrangement $(1 \mathrm{~A})$

\begin{tabular}{|c|c|c|c|c|c|c|c|c|c|c|c|}
\hline \multicolumn{12}{|c|}{ Seating arrangement $(1 \mathrm{~A})$} \\
\hline & & \multicolumn{5}{|c|}{ Pre-service } & \multicolumn{5}{|c|}{ In-service } \\
\hline & & TR1\& & TR3\& & TR5\& & TR7\& & TRs & $\mathrm{T} 1$ & $\mathrm{~T} 2$ & $\mathrm{~T} 3$ & $\mathrm{~T} 4$ & Ts \\
\hline & & TR2 & TR4 & TR6 & TR8 & Total & & & & & Total \\
\hline & Student & - & - & - & 2 & 2 & 2 & 2 & - & 1 & 5 \\
\hline & Desk & - & - & - & - & - & - & 1 & - & - & 1 \\
\hline $1 \mathrm{~A}$ & TOTAL & & & & & 2 & & & & & 6 \\
\hline
\end{tabular}

In relation to the physical conditions of the learning environment, the teacher can do or say something to control or check the visibility, audibility of the presented materials, use the classroom artefacts such as electrical sockets, curtains, and windows, and ensure orderliness. The details regarding the code 1B physical conditions are given in Table 5 below.

Table 5. Physical Conditions (1B)

\begin{tabular}{|c|c|c|c|c|c|c|c|c|c|c|c|}
\hline \multicolumn{12}{|c|}{ Physical Conditions (1B) } \\
\hline & & \multicolumn{5}{|c|}{ Pre-service } & \multicolumn{5}{|c|}{ In-service } \\
\hline & & TR1\& & TR3\& & TR5\& & TR7\& & TRs & $\mathrm{T} 1$ & $\mathrm{~T} 2$ & T3 & $\mathrm{T} 4$ & Ts \\
\hline & & TR2 & TR4 & TR6 & TR8 & Total & & & & & Total \\
\hline & Visibility & 1 & - & - & - & 1 & 1 & - & - & - & 1 \\
\hline & Audibility & - & - & - & 1 & 1 & - & 4 & 4 & 1 & 9 \\
\hline & Artifacts & 1 & 2 & - & 1 & 4 & 5 & 5 & 3 & 13 & 26 \\
\hline & Orderliness & 6 & 1 & 1 & 1 & 9 & - & 1 & 6 & 1 & 8 \\
\hline 1B & TOTAL & & & & & 15 & & & & & 43 \\
\hline
\end{tabular}

As shown in the table, both the pre-service and in-service teachers dealt with the physical wellbeing of the classroom. It is seen that in-service teachers were more concerned with audibility $(n=9)$ than pre-service teachers $(n=1)$. This might be due to the presence of the mentor in the classroom as they were doing their demo lessons. It is a common practice that the mentors warn their classes to sit quietly before the pre-service teachers begin their demo lessons. Therefore, pre-service teachers usually teach to relatively quieter students.

Another difference was in terms of artefacts. While the in-service teachers used an artefact 26 times throughout the data; the pre-service teachers used them 4 times. It must be noted, however, that T4 has half of the total tallies in the artefacts 
category. This was because she frequently used the classroom closet to fetch or put her things. Nevertheless, a pre-service pair could use or refer to a classroom artefact twice at most while an in-service has at least three tallies for this category.

Moreover, the way pre-service and in-service teachers use the classroom artefacts can show qualitative differences. In order to demonstrate these differences, extracts from in-service data and pre-service data will be compared below. The left column belongs to a lesson by a pre-service teacher (TR2) in $4^{\text {th }}$ grade classroom. The right column belongs to a lesson by an in-service teacher (T2) with $7^{\text {th }}$ grades.

Extract 1. Artifacts

\begin{tabular}{ll}
\hline Pre-service & In-service \\
S teacher there is the sunbeam & T2 are you ready. is that all right, we are looking forward to \\
TR2 ((pulling the curtain)) why bother $(h)$ sun shines on the & watching you (.) yes \\
beautiful sit down finished & S \{attempting to give some background about the play $\}$ \\
T2 ((interrupting him)) ok don't explain anything $(0.5)$ & T2 ((to a student near the window)) could you close $($.$) the$ \\
windows. & T2 ((to a couple of students)) shh please be quiet \\
T2 ((to the group at the board)) yes please & ((students act out the play)) \\
\hline
\end{tabular}

In these extracts, both TR2 and T2 use classroom artefacts; TR2 the curtain, and T2, the window. TR2 is concerned with visibility, but she does not notice it until a student warns her. This is in contrast with $\mathrm{T} 2$, who makes an active move to ensure audibility by having the student close the window before an act-out activity begins. Moreover, in TR2's case, teacher does the actual job of pulling the curtain. This puts her in a weaker position in terms of authority, therefore, she tries to re-establish her authority via a humorous comment which refers to a well-known Turkish saying, "The morning sun shines on the bed wetter, and the evening sun shines on the beautiful." In T2's case, the teacher is in the stronger position. We can see the evidence in how she interrupts the student and how she asks the student next to the window to close the window rather than doing it herself. To conclude, we can say that in these instances, the pre-service teacher was reactive in her decision to pull the curtain while the in-service teacher actively chose to do so for the purpose of ensuring audibility.

When we look at the movement patterns of pre-service and in-service teachers, we see that the former has more tallies than the latter in this category. These numbers were created by putting a tally mark each time the teacher moved to a new position during the lesson. The greatest difference is in terms of the times when a teacher moved next to a student desk. This can be for checking a students' work, talking to a student individually, or as a result of the students' calling for the teacher. This was tallied 212 times in the pre-service teachers' data while 95 times in the in-service teachers' data. Especially the TR1\&TR2 pair and TR7\&TR8 pair had unusually big number of tallies. Compare for example with T2 and T4 who visit the students' desks more often than their colleagues. The results are shown in Table 6 below.

Table 6. Movement Pattern (1C)

\begin{tabular}{|c|c|c|c|c|c|c|c|c|c|c|c|}
\hline \multicolumn{12}{|c|}{ Movement Pattern (1C) } \\
\hline & & \multicolumn{5}{|c|}{ Pre-service } & \multicolumn{5}{|c|}{ In-service } \\
\hline & & TR1\& & TR3\& & TR5\& & TR7\& & TRs & $\mathrm{T} 1$ & $\mathrm{~T} 2$ & T3 & $\mathrm{T} 4$ & Ts \\
\hline & & TR2 & TR4 & TR6 & TR8 & Total & & & & & Total \\
\hline & Tdesk & 1 & 6 & 17 & 1 & 25 & 15 & - & 5 & 1 & 21 \\
\hline & St desk & 73 & 23 & 75 & 41 & 212 & 7 & 42 & 13 & 33 & 95 \\
\hline & Front left & 15 & 2 & 22 & 8 & 47 & 7 & 13 & 4 & 5 & 29 \\
\hline & Front middle & 43 & 23 & 38 & 20 & 124 & 29 & 25 & 10 & 45 & 109 \\
\hline & Front right & 26 & 2 & 8 & 16 & 52 & 54 & 8 & 11 & 40 & 113 \\
\hline & Back & - & 1 & 3 & 1 & 5 & 10 & 4 & 3 & 6 & 23 \\
\hline & Wander & 11 & - & 5 & 1 & 17 & 8 & - & - & 4 & 12 \\
\hline $1 \mathrm{C}$ & TOTAL & 169 & 57 & 168 & 88 & 482 & 130 & 92 & 46 & 134 & 402 \\
\hline
\end{tabular}

Another point that draws the attention is the differences in terms of using the back of the classroom. The back of the classroom was used at least once except for TR3\&TR4's lessons.

\subsection{Activities}

Table 7. Activities

\begin{tabular}{lllllll}
\hline & Pre-service & & In-service & \multicolumn{2}{c}{ Total } \\
& $\mathbf{n}$ & $\mathbf{\%}$ & $\mathbf{n}$ & $\mathbf{\%}$ & $\mathbf{n}$ & $\mathbf{\%}$ \\
Set up interaction (2D) & 70 & 23 & 129 & 43 & 199 & 66 \\
Finish an activity (2E) & 33 & 11 & 32 & 11 & 65 & 22 \\
Give instructions (2F) & 9 & 3 & 16 & 5 & 25 & 8 \\
Amend problems (2G) & 5 & 2 & 6 & 2 & 11 & 4 \\
\hline
\end{tabular}


The second category is "activities". There were a total of 300 tallies in this category. The details are given in Table 7 below. A tally was made when an activity is finished. Approximately same number of activities was finished in both sets of the data, however, in-service teachers switched between interaction types (listen, read-aloud, question-answer, etc) more often than pre-service teachers. For example, within a single activity a teacher can set up a read-aloud, ask a question, do repeat-after-me and then continue the read aloud, resulting in a 2D tally for each time the interaction pattern changes. Pre-service teachers seem to stick to a plan and cannot use the interaction types as versatile as the in-service teachers.

A teacher can finish an activity by simply starting a new activity, or by signposting what has been done and what is to come now. It is also possible that the next activity is negotiated with the students. Table 8 below shows the results in more detail.

Table 8 . Finish an activity (2E)

\begin{tabular}{|c|c|c|c|c|c|c|c|c|c|c|}
\hline \multicolumn{11}{|c|}{ Finish an activity (2E) } \\
\hline & \multicolumn{5}{|c|}{ Pre-service } & \multicolumn{5}{|c|}{ In-service } \\
\hline & TR1\& & TR3\& & TR5\& & TR7\& & TRs & $\mathrm{T} 1$ & $\mathrm{~T} 2$ & T3 & $\mathrm{T} 4$ & Ts \\
\hline & TR2 & TR4 & TR6 & TR8 & Total & & & & & Total \\
\hline Newact & 5 & 5 & 3 & 7 & 20 & 2 & 1 & 3 & 5 & 11 \\
\hline Signpost & - & 3 & 1 & 2 & 6 & 2 & 4 & 4 & 3 & 13 \\
\hline Abrupt & 2 & - & 2 & 2 & 6 & 2 & - & - & - & 2 \\
\hline Negotiate & - & - & - & 1 & 1 & 2 & 2 & 2 & - & 6 \\
\hline
\end{tabular}

As seen in the table, although the codes in this category sum up to similar numbers for pre-service and in-service teachers, the distribution shows great difference. When we look at closely how exactly they finished an activity, we can see that pre-service teachers often did so by announcing that a new activity was coming (e.g. by saying "we pass to the next activity") or passing abruptly; without even announcing it. In-service teachers on the other hand, tended to signpost what had been done so far and what would be done next more often than pre-service teachers.

Pre-service teachers gave fewer instructions than in-service teachers. For example saying only "ok next exercise" or beginning the first item in the exercise as an example, the teachers could start an activity without any explicit instruction. When they did, there were also qualitative differences in how the instructions were given. The extract below was chosen to demonstrate these differences. In extract 2 below, both the pre-service and in-service teacher begin by reminding the page number on the course book. TR5 is working with $4^{\text {th }}$ graders and T4 is working with $5^{\text {th }}$ graders.

Extract 2. Instructions

\begin{tabular}{ll}
\hline Pre-service & In-service \\
TR5 yes thank you (.) ok page twenty seven yes the first one & T4 ok page one hundred and ten ((writes 110 on the board)) \\
is (.) done I'm reading (.) the weather is sunny today you & page one hundred and ten shh (.) yes now here both the ages \\
don't want to stay at home all day you want to go for a & and the months and numbers are scrambled (.) first we fill in \\
picnic what do you say to your mother what about going for & the table below according to the passage for example let's \\
a picnic (.) yes your turn the second one is- (.) yes (.) look at Mert how old is he how old is he & lo \\
anybody (.) ok you have five minutes (.) complete the & S2 nine \\
activity then we will- (.) ok & T4 in English please \\
S1 shall we do & S1January \\
TR5 yes five minutes you have & T4 shh ok how old is Mert how old is Mert Tuna \\
S2 teacher, may I get a pencil & S2 he is nine years old \\
TR5 ok & T4 he is nine years old and when is his birthday when is his \\
S3 teacher, can you help me & birthday İsmail \\
TR5 ((checks individual sts)) using the same structure(.) you & S3 er \\
will say what he wants to do here ok & T4 it is \\
S3 haa & S3 it is January \\
TR5 for example what about (.) playing (.) chess & T4 it is in January fill in the-first fill in the table ((checking \\
& the work of individual students)) \\
\hline
\end{tabular}

In TR5's case, he reads the course book's instruction aloud once and then he asks for volunteers for the next item immediately. When nobody can volunteer, he gives the students five minutes to work on the exercise. We can see that the students cannot begin the activity right away. S1 checks for confirmation, S2 has not got a pencil to begin, and S3 apparently has not understood the book's instruction. Thus he gives the individual student the instruction in Turkish and provides an example. The rest of the class does not hear these explanations and examples. Contrary to TR5, who deals with students' needs reactively, we can observe T4 actively taking precautions for a problem-free activity. First, she makes sure that everyone is on the same page. She not only announces it, but also writes it on the board. Secondly, she does not read the book's instructions; instead, she uses the thinking aloud technique to demonstrate how to handle the activity. She divides the activity into steps. She demonstrates where to look at and how to go about doing the activity. She makes sure that everyone can follow by asking students questions. S1 volunteers for the first question but he cannot answer it. She picks the more successful students by name to make sure that the rest of the class can see a good example. 
Once she is sure that the instruction is understood well, she begins the allotted time by repeating the instruction: "fill in the table" in the last line. The dramatic difference between the ways the two teachers gave instructions was not necessarily reflected in the observed consequences. After the instructions, on the surface, it was observed that both teachers had busy students for five minutes and they were visiting students' desks and talking with the students silently. In reality, TR5 was still explaining the instructions in Turkish for each individual student during those five minutes contrary to T4, who was monitoring students' work, and correcting mistakes. While TR5's students were still struggling to understand what to do, T4's students could spend all of the allotted time for actually doing the exercise.

\subsection{Authority}

The third category in Scrivener's (2005) model is Authority. In this model, authority is understood as how the teacher makes the students pay attention, stay on task, and participate. See table 9 for more details.

Table 9. Authority

\begin{tabular}{lllllll}
\hline & Pre-service & & In-service & \multicolumn{2}{c}{ Total } \\
& $\mathbf{n}$ & $\mathbf{\%}$ & $\mathbf{n}$ & $\mathbf{\%}$ & $\mathbf{n}$ & $\mathbf{\%}$ \\
Gather attention (3H) & 37 & 11 & 38 & 11 & 75 & 22 \\
Task progress (3I) & 14 & 4 & 30 & 9 & 44 & 13 \\
Nominate (3J) & 60 & 17 & 163 & 47 & 223 & 64 \\
Student gets permission (3K) & 2 & 0 & 2 & 1 & 31 & 1 \\
\hline
\end{tabular}

The biggest difference in this category is in terms of nominating students. Since the pre-service teachers had spent less time with the students, they often did not know the students' names. Therefore, they tended to let them self-select during the activities rather than allotting turns using their names.

When the teacher wants to gather attention during a task, many strategies are available. For example, the teacher can use chunks such as "listen to me", call a student by name like "Ali look here", and even may be make a humorous comment or joke to gather the class attention.

Table 10. Gather attention $(3 \mathrm{H})$

\begin{tabular}{|c|c|c|c|c|c|c|c|c|c|c|c|}
\hline \multicolumn{12}{|c|}{ Gather attention $(3 \mathrm{H})$} \\
\hline & & \multicolumn{5}{|c|}{ Pre-service } & \multicolumn{5}{|c|}{ In-service } \\
\hline & & TR1\& & TR3\&T & TR5\&T & TR7\&T & TRs & $\mathrm{T} 1$ & $\mathrm{~T} 2$ & $\mathrm{~T} 3$ & $\mathrm{~T} 4$ & Ts \\
\hline & & TR2 & $\mathrm{R} 4$ & R6 & $\mathrm{R} 8$ & Total & & & & & Total \\
\hline & Chunk & 2 & 9 & 1 & 10 & 22 & 3 & 5 & 4 & 2 & 14 \\
\hline & Name & 14 & - & - & - & 14 & - & 3 & 10 & 2 & 15 \\
\hline & Joke & 1 & - & - & - & 1 & 8 & - & - & 1 & 9 \\
\hline $3 \mathrm{H}$ & TOTAL & 17 & 9 & 1 & 10 & 37 & 11 & 8 & 14 & 5 & 38 \\
\hline
\end{tabular}

It was found that even if they gathered attention for the same number of times, the strategies that the pre-service and in-service teachers used were different. In-service teachers could use chunks, names or jokes to gather attention. However, pre-service teachers relied more on chunks rather than names or jokes. Only one pair of pre-service teachers used students' names as an attention gathering strategy and their lesson was the only one in which a joke was used with the purpose of gathering attention. The other three pairs relied entirely on chunks to gather students' attention.

There was also difference in the frequency of task progress checks. In-service teachers seemed to control task progress more. They did so by warning off-task students, praising on-task ones, and reminding the rules without referring to individual students. Table 11 shows the details.

Table 11. Task progress (3I)

\begin{tabular}{|c|c|c|c|c|c|c|c|c|c|c|c|}
\hline \multicolumn{12}{|c|}{ Task progress (3I) } \\
\hline & & \multicolumn{5}{|c|}{ Pre-service } & \multicolumn{5}{|c|}{ In-service } \\
\hline & & TR1\& & TR3\& & TR5\& & TR7\& & TRs & $\mathrm{T} 1$ & $\mathrm{~T} 2$ & $\mathrm{~T} 3$ & $\mathrm{~T} 4$ & Ts \\
\hline & & TR2 & TR4 & TR6 & TR8 & Total & & & & & Total \\
\hline & Off-task & 1 & 1 & 3 & - & 5 & 1 & 3 & 3 & 3 & 10 \\
\hline & On-task & - & 1 & - & - & 1 & - & 2 & 3 & - & 5 \\
\hline & remind & 3 & 5 & - & - & 8 & 4 & 1 & 9 & 1 & 15 \\
\hline $3 \mathrm{I}$ & TOTAL & & & & & 14 & & & & & 30 \\
\hline
\end{tabular}

As shown in the table, the pre-service teachers paid less attention to on-task students compared to in-service teachers. They warned individual off-task students or they loudly reminded the rules when it was necessary. It is worth reminding here that none of the observed lessons contained immediately apparent classroom management problems. Pre-service teachers had to deal with task progress less compared to the in-service teachers because either no problem arose, or the problems were solved immediately before the pre-service teacher had to attempt solving them. The reason for the pre-service teachers' having more obedient and on-task students can be explained by the presence of the mentor in the classroom. It is a common practice that mentors talk to their classes before the demo lessons of the pre-service teachers 
and want them to participate well. The mentors can even warn the off-task ones by eye contact during the demo lessons. Since in-service teachers typically do not have such a second source of authority in the class, they have to manage the moment-by-moment participation more actively.

\subsection{Critical Moments}

The category of Critical moments includes the starting and the finishing of the lesson as well as any unexpected event. These special times need a special type of classroom management. Especially the start and the finish of the lessons were different (Table 12).

Table 12. Critical Moments

\begin{tabular}{lllllll}
\hline & Pre-service & & In-service & \multicolumn{2}{c}{ Total } \\
& $\mathbf{n}$ & $\mathbf{\%}$ & $\mathbf{n}$ & $\mathbf{\%}$ & $\mathbf{n}$ & $\mathbf{\%}$ \\
Start lesson (4L) & 8 & 26 & 12 & 39 & 20 & 65 \\
Daily business (4M) & 0 & 0 & 1 & 3 & 1 & 3 \\
Finish lesson (4N) & 3 & 10 & 7 & 22 & 10 & 32 \\
Unexpected event (4O) & 0 & 0 & 0 & 0 & 0 & 0 \\
\hline
\end{tabular}

The teacher can signpost the day's work, greet the students, have a small chat, revise previous work, announce the topic, and use a combination of these strategies to start a lesson. It was found that in-service teachers used more varied strategies than the pre-service teachers. The pre-service teachers relied more on just announcing the topic like "We will study ... today". As in starting the lesson, the in-service teachers could use more varied techniques to finish the lesson compared to the pre-service teachers. The numbers of tallies for the two subcategories were presented in Table 13.

Table 13. Start lesson (4L) and Finish lesson (4N)

\begin{tabular}{|c|c|c|c|c|c|c|c|c|c|c|c|}
\hline \multicolumn{12}{|c|}{ Start lesson $(4 \mathrm{~L})$} \\
\hline & & \multicolumn{5}{|c|}{ Pre-service } & \multicolumn{5}{|c|}{ In-service } \\
\hline & & TR1\& & TR3\& & TR5\& & TR7\& & TRs & $\mathrm{T} 1$ & $\mathrm{~T} 2$ & $\mathrm{~T} 3$ & $\mathrm{~T} 4$ & Ts \\
\hline & & TR2 & TR4 & TR6 & TR8 & Total & & & & & Total \\
\hline & Signpost & - & - & - & - & - & 1 & - & - & 1 & 2 \\
\hline & Greet & - & - & - & 2 & 2 & 1 & - & 1 & - & 2 \\
\hline & Sm.chat & - & - & - & - & - & 1 & 1 & - & - & 2 \\
\hline & Revise & - & - & - & - & - & - & - & - & 1 & 1 \\
\hline & Start & 2 & 1 & 2 & - & 5 & 1 & 1 & - & - & 2 \\
\hline & Topic & - & 1 & - & - & 1 & 2 & - & 1 & - & 3 \\
\hline $3 \mathrm{I}$ & TOTAL & & & & & 8 & & & & & 12 \\
\hline \multicolumn{12}{|c|}{ Finish lesson (4N) } \\
\hline & Signpost & - & 1 & - & - & 1 & - & 2 & - & 1 & 3 \\
\hline & Hmwrk & 1 & 1 & - & - & 2 & 1 & 1 & 1 & 1 & 4 \\
\hline $3 \mathrm{I}$ & TOTAL & & & & & 3 & & & & & 7 \\
\hline
\end{tabular}

3.6 Tools and Techniques

The Tools and Techniques category includes the classroom management tips using your body language, your voice, the language you use and other classroom equipment such as the board to facilitate classroom management (Table 14).

Table 14. Tools and Techniques

\begin{tabular}{lllllll}
\hline & Pre-service & \multicolumn{2}{c}{ In-service } & \multicolumn{3}{c}{ Total } \\
& $\mathbf{n}$ & $\mathbf{\%}$ & $\mathbf{n}$ & $\mathbf{\%}$ & $\mathbf{n}$ & $\mathbf{\%}$ \\
Board (5P) & 7 & 7 & 18 & 17 & 25 & 24 \\
Materials (5Q) & 9 & 8 & 35 & 34 & 44 & 42 \\
Volume (5R) & 0 & 0 & 7 & 7 & 7 & 7 \\
Silence (5S) & 0 & 0 & 0 & 0 & 0 & 0 \\
Language (5T) & 9 & 9 & 19 & 18 & 28 & 27 \\
\hline
\end{tabular}

Neither pre-service nor in-service teachers used silence as a classroom management tool during the observed sessions. In-service teachers made more adjustments to their language and speaking volume for classroom management purposes than the pre-service teachers. This difference might be due to two reasons; first, in-service teachers might have become more able in doing such adjustments due to their teaching experience. Secondly, it might be simply that the pre-service teachers had more silent and attentive students than the in-service teachers, so they needed to do such adjustments less. Of course, a combination of both reasons might have taken a role in the difference, as well.

In terms of using the board and other materials, these categories yielded similar results to the activities category. Just like the activities, the materials are used in a more versatile and flexible way by the in-service teachers than the pre-service ones.

\subsection{Working with People}

The last category is working with people. In this category, how the teacher manages the class group dynamics is handled. This 
includes allowing and responding to student initiation and caring for them as whole persons as well as group relations and rapport.

Table 15. Working with people

\begin{tabular}{lllllll}
\hline & Pre-service & & In-service & & Total \\
& $\mathbf{n}$ & $\mathbf{\%}$ & $\mathbf{n}$ & $\mathbf{\%}$ & $\mathbf{n}$ & $\boldsymbol{\%}$ \\
Student initiation (6U) & 76 & 23 & 148 & 46 & 224 & 69 \\
Gauge students' feelings (6V) & 0 & 0 & 2 & 1 & 2 & 1 \\
General feedback (6W) & 1 & 0 & 13 & 4 & 14 & 4 \\
Classroom history (6Y) & 0 & 0 & 1 & 0 & 1 & 0 \\
Individual support (6Z) & 51 & 16 & 33 & 10 & 84 & 26 \\
\hline
\end{tabular}

Student initiation code was formed whenever a student starts talking without being asked a question or asks a question that is not related to the current concern of the class. The teacher can ignore the initiation and go on the current topic or react to the initiation by taking up the topic or rejecting it. Such initiation was observed more often in the in-service teachers' lessons. However, some inconsistencies in the distribution of the tallies make interpretation difficult. Table 16 shows the exact tallies for each observation.

Table 16. Student initiation (6U)

\begin{tabular}{|c|c|c|c|c|c|c|c|c|c|c|c|}
\hline \\
\hline \multicolumn{2}{|c|}{$\begin{array}{l}\text { Student initiation (6U) } \\
\text { Pre-service }\end{array}$} & \multicolumn{5}{|c|}{ Pre-service } & \multicolumn{5}{|c|}{ In-service } \\
\hline & & TR1\& & TR3\& & TR5\& & TR7\& & TRs & $\mathrm{T} 1$ & $\mathrm{~T} 2$ & T3 & $\mathrm{T} 4$ & Ts \\
\hline & & TR2 & TR4 & TR6 & TR8 & Total & & & & & Total \\
\hline & Answers & $\begin{array}{l}36 \\
(86 \%)\end{array}$ & $\begin{array}{l}18 \\
(95 \%)\end{array}$ & $\begin{array}{l}5 \\
(71 \%)\end{array}$ & $\begin{array}{l}4 \\
(50 \%)\end{array}$ & & $\begin{array}{l}34 \\
(77 \%)\end{array}$ & $\begin{array}{l}2 \\
(100 \%)\end{array}$ & $\begin{array}{l}55 \\
(78 \%)\end{array}$ & $\begin{array}{l}26 \\
(79 \%)\end{array}$ & \\
\hline & Ignores & $\begin{array}{l}6 \\
(14 \%)\end{array}$ & $\begin{array}{l}1 \\
(5 \%)\end{array}$ & $\begin{array}{l}2 \\
(29 \%)\end{array}$ & $\begin{array}{l}4 \\
(50 \%)\end{array}$ & & $\begin{array}{l}10 \\
(23 \%)\end{array}$ & - & $\begin{array}{l}14 \\
(22 \%)\end{array}$ & $\begin{array}{l}7 \\
(21 \%)\end{array}$ & \\
\hline $3 \mathrm{I}$ & TOTAL & 42 & 19 & 7 & 8 & 76 & 44 & 2 & 69 & 33 & 148 \\
\hline
\end{tabular}

As seen in the table, T2 had only two student initiations. This means that throughout the two consequent lessons, students initiated a topic or asked a question that is unrelated to the current concern of the class only twice; and all the other topics and concerns in the lessons were brought up in the control of T2. This is fewer than the number of initiations in all of her in-service colleagues' and the pre-service pairs' lessons.

In the pre-service teachers' data, TR2\&TR3 had a total of 42 student initiations. This number is more than all the other pre-service pairs' lessons. We can even say they got a nearly equal number of initiations to T1's lesson. The other three pairs had fewer student initiations compared to T1, T3, and T4. We can infer that in typical conditions, the general tendency was that student initiation was observed less in pre-service teachers' lessons compared to the in-service teachers' lessons.

Moreover, there was difference in the way these student initiations were handled by the teachers. For example, although TR2\&TR3 pair had a close rate of student initiation to that of T1's, they ignored only $14 \%$ of these, while T1 ignored $23 \%$ of the student initiations. In fact, there is a consistency in the ignoring rates of T1, T3 and T4; all of them ignored about $20 \%$.

Extract 3 was chosen from the data to demonstrate the potential effects of such differences. Both of the extracts come from an episode whereby the teacher has given some time to complete the exercise. This is potentially a suitable time for student initiation since the teacher is waiting silently. TR2 is with $4^{\text {th }}$ graders while T3 is with $5^{\text {th }}$ graders.

Extract 3. Student initiations

\begin{tabular}{ll}
\hline Pre-service & In-service \\
S1teacher I've finished these & S1 teacher when will we have the exam \\
TR2ok we are not doing those right now a blue pencil a blue & T3 I told you I will announce the preceding week please \\
pencil a blue pencil & write carefully pay attention to spelling \\
S2 I cannot keep up & S2 teacher shall we do these \\
TR2 ok we are writing blue pencil we haven't passed the & T3 let's wait children \\
other one yet & T3 ((to the class)) have we finished yes meanwhile let me \\
S3teacher I've done it again & play once more let's listen it again \\
TR2ok don't do yet wait finished, a green pencil a green & S2 shall I write up to twenty-thirty \\
pencil & S3 you can write up to eternity \\
& S4 so easy \\
& computer: first second third fourth (...)
\end{tabular}

The students begin talking to the teacher three times in TR2's extract, none of which were ignored. All three initiations are students' feedback about their own progress in the task. T3 also answers such feedback when S3 asks something about the following exercise but he does not answer the other comments from the same student. Since the teacher chooses not to respond, S3 and S4 join in but T3 ignores them too, just starting the listening passage on the computer. In addition, we can see in T3's extract that a student asks about the exam. Pre-service teachers typically lack such shared 
history or future arrangements with the students. This might explain the lack of student initiation in their lessons.

It was observed that the in-service teachers preferred to address the whole class rather than dealing with individual students while the pre-service teachers preferred to deal with individuals more. For example, during the instructions in the extract 2 above, the pre-service teacher reads aloud the instruction and then visits individual desks to make explanations and help. On the other hand, the in-service teacher prefers to make explanations and give examples loudly so every student can hear them. Once the activity starts, the in-service teacher does not interfere unless necessary, just monitors the progress, the pre-service teacher, talks to each student and explains to all students one by one.

\section{Discussion}

In this study, sixteen lessons by four in-service and eight pre-service teachers were compared according to six categories in a framework based on Scrivener's (2005) model. The detailed analysis that was reported above showed that all of the six categories were observable without exception in all the teachers' lessons. Regardless of the teacher, topic or level of the class, classroom management seems to exist in any teaching and learning situation with all its aspects. Although it is so prominent in the classroom, Evertson and Weinstein (2006) remark that classroom management has been neglected in academic works and they remind us that "if classroom management is to assume its rightful place in pre-service education, we need to be cognizant of the many strands of inquiry that relate to and enrich our understanding of this multidimensional construct" (p.5).

The usefulness of the tallying system in understanding the classroom management differences can be discussed. The categories which had the most tallies were Grouping and Seating; Activities; Authority; and Working with people categories. Although these top categories are in line with the general description of what classroom management entails in the literature (Emmer \& Stough, 2001; Tsui, 2003; Burden \& Cooper, 2004; Wright, 2005; Evertson \& Weinstein, 2006), a bigger number of tallies does not necessarily entail bigger importance compared to categories with fewer tallies. The number of tallies often depends on the nature of the activity rather than its importance. For example, a tally was formed whenever a teacher moved to a new position to create the information about movement patterns in grouping and seating category. Critical moments category on the other hand, was tallied only at the beginning and ending of the lessons, resulting in fewer tallies. But this does not mean that how critical moments are managed is less important issue in the management of the classroom. Moreover, the number of tallies still needs interpretation because the more tallies in a category do not necessarily mean that teacher was better in terms of that category. For example, T4's use of the classroom cupboard so many times increased her tallies for artefacts subcategory. Despite these limitations, the tallying system revealed different tendencies in each category for the two groups of teachers. Therefore, it can be argued that the tallying system successfully showed that classroom management in pre-service teachers' demo lessons are not the same as the classroom management in the in-service teachers' lessons.

When we compare the two groups in terms of grouping and seating category, firstly, pre-service teachers seemed not to make as many changes to students' places or seating, dealt with classroom artefacts less, and used the back of the class less often than in-service teachers. Back of the class is associated with extreme control and power as a type of "supervisory space" (Lim, O'Halloran \& Podlasov, 2012). Unfortunately, there are not many studies to compare and explain these differences. One way of looking at the issue could be ownership studies and property theories. Accordingly, peoples' action zones and personal spaces can differ depending on their ownership of the space and properties (Schnall et.al. 2005). Secondly, the pre-service teachers seemed to deal with audibility and visibility reactively rather than proactively. "In general, proactive strategies are those behaviours that a teacher can use in order to lessen the likelihood of a child demonstrating inappropriate behaviour, and involve altering a situation before problems escalate. Proactive discipline plans can be conceptualized as being preventative and taking a positive approach to classroom management" (Clunies-Ross, Little \& Kienhuis, 2008, p.695). In-service teachers were more proactive in their decisions related to the visibility and audibility during their lessons. Thirdly, although they had not taken pro-active measures, pre-service group had more silent classes. According to Marshall (2005) "the presence of a top-level authority figure in the classroom usually reduces discipline problems and results in a more orderly lesson than students generally experience" (p. 729). Therefore, this finding can be attributed to the presence of the mentor and the supervisor in the classroom during the recording of the demo lessons.

In terms of the Activities category, the findings indicate that in-service teachers can switch between modes of interaction in a more versatile and flexible way whereas pre-service teachers tend to stick to their plan and teach against the grain. This can be explained by the lack of expertise. It can be expected that teachers' attention will shift from self to instruction as they gain experience (Wright, 2005). Also Hayes (1999) found a similar inflexibility in the participants' lessons because they would "have to justify it to an external verifier" (p.345). It was also noticed that pre-service teachers used less signposting in the transitions, and they gave less instructions and low-quality instructions. Despite these differences, both groups had apparently problem-free lessons. 
In the Authority category, a similar point was noticed. Task progress was controlled less in pre-service teachers' lessons yet no problem seems to have aroused. Another finding in this category revealed that pre-service teachers had to rely on chunks rather than students' names or jokes in gathering their attention and used students' names less in turn allocations. These differences could have stemmed from their lack of history with the classes. Sarıçoban (2005) lists establishing rapport as one of the basic considerations to create a positive atmosphere in the classroom. Knowing students' names and sharing a background with them can improve rapport considerably.

In terms of Critical moments and Tools and Techniques categories, the differences lied in the variety of strategies and tools. The in-service teachers tended to use more types of strategies to begin and end lessons, more variety of tools and techniques and in a more versatile and flexible way. Similar findings were found in other studies such as Reupert and Woodcock (2010); Ünal and Ünal (2012); and Ragawanti (2015). These differences can be explained by the stages of teacher development theories (Wright, 2005). The end result, however, were observed to be the similar for both groups; pre-service teachers seemed to have problem-free lessons as the in-service teachers despite the differences in how they handled critical moments and classroom tools.

The Working with people category had the most inconsistency in the tallies may be because the personal teaching style affects the relations with the students most. The general tendency of in-service teachers to ignore about $20 \%$ of the student initiations was not observed as consistently among the pre-service teachers. Waring, Reddington and Tadic (2016) remind us that "the urgency to reduce teacher control should not diminish the necessity and importance of that control" (p.37). In their data, they found "cases in which teacher assertions of control preserve a 'quiet' student's right to speak, reign in off-topic side talk, and re-focus learners on the task at hand" (p.37). Apparently, the pre-service teachers had not gained the necessary insight about responding to students' initiations.

Having discussed the results category-by category, some themes that cut across the categories meet the eye. Firstly, there are some results that can be attributed to the lack of history with the class on the part of the pre-service teachers. In extract 2, TR5 could not adjust his instructions to the group. Inexperience and also not knowing the students' level might have caused this problem. In addition, it was found that pre-service teachers did not use the students' names as many times as the in-service teachers. Clearly, they had not got the opportunity to learn the students' names. Pre-service teachers used less signposting, less general feedback compared to in-service teachers. This might be due to the fact that they did not know their level, their background, previous lesson. Having shared the history with the class, the in-service teachers could chat with the students and signpost to show how the lesson is related to the other lessons at the beginning more often. They could revise the previous lesson, use jokes to gather attention and give homework for the next lesson as they finish. So in-service relied on their relations with and knowledge of the students in the lesson while pre-service teachers relied more on their academic knowledge. This is in line with Merç \& Subaşı's (2015) finding that pre-service teachers rely on their knowledge from methodology lessons.

The second theme that repeatedly emerged in the discussion was the surprising finding that although the classes were managed differently, neither of the groups seemingly had any problems in terms of classroom management. Pre-service teachers controlled the task progress less often, dealt with audibility less often, used voice and language adjustments less. The reason might be that they had relatively more obedient less disruptive students and quieter classrooms due to the mentor's existence in the classroom during the demo lessons (Marshall, 2005). Another reason might be that the students perceived the pre-service teacher as a guest to be pleased. They might have wanted to cause less trouble. For example, it was observed that the students got permission from the pre-service teachers less often. Mentors have a dual role whereby the teacher is at the same time the teacher of the class and the teacher of the teacher (Korth, Erickson, Hall \& Martin, 2006). Mentors might be concerned with their students' learning and interfere with classroom management in order to help the pre-service teachers by providing them a problem-free class to teach. There are lots of roles for the mentor, but these might not be well-defined all the time. When this is the case, mentors cannot be useful to the full potential (Hall, Draper, Smith \& Bullough, 2008). It has been shown that the actions of the mentor can play an important role in the success of the pre-service teacher in learning teaching (Evertson \& Smithey, 2000). Therefore, some extra effort is required in order to communicate better the importance and learning aims of the teaching practice to the mentors and to clarify the roles and responsibilities better both to the mentors and their students.

Lastly, there is usually an observer present in the pre-service teacher's lesson to give him or her points on their teaching performance. This observer can be the instructor from the university, or the mentor, and it is so important that the lesson looks good to the observer to get higher points. The point of the demo lesson can easily become "showing the lesson" rather than "teaching the students" (Personn \& Yiğitoğlu, 2015). In this study, it was found that in-service teachers switched between interaction types and materials more often while the pre-service teachers tended to stick to apply their lesson plan more rigidly. In the critical moments of the lesson, the pre-service teachers just began and just finished without any other interaction more often than in-service teachers. They allowed for less student initiation, negotiated less between the activities. When they gave instructions, they used short, bookish instructions. The pre-service teachers 
visited more desks, and talked to individual students more during the exercises. It seems, thus, that pre-service teachers were more self-oriented in planning and applying the lessons. In-service teachers planned their lessons for students' benefit and they considered the students' experience more important as they plan. In addition, asking students' opinions and negotiating what to do next was seen more often in in-service teachers' lessons. In that respect, we can conclude that pre-service teachers are more rigid in following and applying their lesson plans compared to in-service teachers. Again, this makes us think that they did the lesson for the sake of the show, and not for the sake of student learning. All these indicate that the in-service teachers had more concern for students' contributions. The pre-service teachers, on the other hand, seem to be more concerned about applying their lesson plan well. This resonates with Wolff, Bogert, Jarodzka and Boshuizen (2015)'s finding that inexperienced teachers disregard the quality of learning and pay more attention to compliance and desired behaviour in interpreting classroom events, which means "missed opportunities for students' learning success" (p.83).

The findings of this study imply that, the demo lessons, which are usually the trainee's one and only chance to get their grades in the school practice lesson, can easily turn into "a show" for the observers rather than a lesson in which learners learn. Their classrooms might be unnaturally obedient, silent and participating out of politeness or fear of the mentor. Not knowing the classroom well, the supervisor might think that a demo lesson went well. May be even worse, the pre-service teachers themselves might not realize that their management skills were poor. As a result, the classroom management issues might not be available to the pre-service teachers for reflection.

One solution can be prolonged engagement on the part of the pre-service teachers and the university instructors. The pre-service teachers should find the opportunity to get to know their pupils better. In Kagan's (1992) model of professional growth, "acquiring knowledge of the pupils" and "using that knowledge to modify and reconstruct their personal images of self-as-teacher" are two of the primary tasks. The school experience time in the curriculum could be extended (Macias \& Sanches, 2015; Sarıçoban, 2016). But only observation might not suffice for reflection; real experience is required. In order to remove power imbalance, the trainees can be given more responsibility. By this means, they can get to know their classrooms better, have the time to learn students' names, and therefore have more strategies of classroom management at their disposal. It must be noted, however, that more experience does not necessarily mean better skills. Cabaroğlu (2012) found that after years of experience, classroom management is still the biggest issue for most teachers. In addition, İnceçay and Keşli-Dollar's (2012) study revealed that even experienced teachers were not self-aware about their classroom management. What they claim to do was different from what they actually did in their classrooms.

Another solution can be informed observation. This kind of observation is not just based on observing and filling out checklists. As many instances in this research have shown, on the surface, very similar results can be yielded and the differences can only be seen upon closer inspection. The pre-service teachers should observe skilled teachers, and carry out detailed analyses of their own recordings to reflect on them. As Emmer and Stough (2001) pointted out, "knowledge of effective classroom management should include adequate conceptualization rather than being learned as discrete concepts and skills, and should give developing teachers a research-based heuristic for examining and formulating their views on management" (p.109). Therefore, including the pre-service teachers in research projects that include informed observation might improve the teaching practice course.

Further research to investigate the effects of prolonged engagement and informed observation should be carried out. In addition, the findings of this study indicate some negative effects of the mentor and supervisor on the authenticity of the teaching situation. In the literature, supervisors are usually investigated in terms of their positive effects to the process (e.g. Caires, Almeida \& Vieira, 2012). There is the need for studies to investigate supervisor and mentor effects from a broader perspective.

A limitation of this study is that these differences between the pre-service and in-service teachers' classroom management can be attributed to many individual differences both across the Ts and TRs groups and among the members of each group. Every teacher has formed their own style of teaching based on many factors such as previous education and teaching experience. There is some evidence that successful classroom management can be linked to certain aspects of the teacher education (Martin, 2004) rather than the amount of teaching experience (İnceçay \& Keşli-Dollar, 2012). Moreover, regardless of the background of the pre- and in-service teachers who participated in this study, the resulting learning atmospheres looked problem-free in terms of classroom management. Therefore, we cannot know how much of the differences between the in-service and pre-service group can be attributed to these factors. In order to find out such effects, experimental and longitudinal studies can be carried out.

\section{Conclusion}

In conclusion, this study showed that the pre-service teachers and the in-service teachers manage their classes differently. Therefore, demo lesson experience might not provide a truly authentic teaching situation for the pre-service 
teachers to practice their classroom management skills. .This is not - by any means - to say that the pre-service should manage their classrooms just like the in-service, nor is it to say that all the in-service teachers in this study exhibited exemplary classroom management during the observed sessions. The existence and the nature of the differences are attributable to the specific procedural decisions taken for the teaching practice course. The findings of this article light up some ideas about the potential side-effects of such procedural decisions.

\section{References}

Brophy, J. (2006). History of research on classroom management. In C. M. Evertson \& C. S. Weinstein (Eds.). Handbook of Classroom Management: Research, practice, and contemporary issues (pp. 17-43). New York: Routledge.

Burden, P. R., \& Cooper, J. M. (2004). An educator's guide to classroom management. Boston: Houghton Mifflin.

Cabaroğlu, N. (2012). Prospective EFL teachers' perceptions of classroom management and misbehavior. Çukurova University Faculty of Education Journal, 41(1), 117-132.

Caires, S., Almeida, L., \& Vieira, D. (2012). Becoming a teacher: Student teachers' experiences and perceptions about teaching practice. European Journal of Teacher Education, 35(2), 163-178. https://doi.org/10.1080/02619768.2011.643395

Clunies-Ross, P., Little, E., \& Kienhuis, M. (2008). Self-reported and actual use of proactive and reactive classroom management strategies and their relationship with teacher stress and student behavior. Educational Psychology, 28(6), 693-710. https://doi.org/10.1080/01443410802206700

Emmer, E.T., \& Stough, L.M. (2001). Classroom management: A critical part of educational psychology, with implications for teacher education. Educational Psychologist, 36(2), 103-112. https://doi.org/10.1207/S15326985EP3602_5

Evertson, C. M., \& Smithey, M. W. (2000). Mentoring effects on protégés' classroom practice: An experimental field study. The Journal of Educational Research, 93(5), 294-304. https://doi.org/10.1080/00220670009598721

Evertson, C. M., \& Weinstein, C. S. (2006). Classroom management as a field of inquiry. In C.M. Evertson \& C.S. Weinstein (Eds.). Handbook of Classroom Management: Research, practice, and contemporary issues (pp. 3-15). New York: Routledge.

Hall, K. M., Draper, R. J., Smith, L. K., \& Bullough, R. V. (2008). More than a place to teach: Exploring the perceptions of the roles and responsibilities of mentor teachers. Mentoring \& Tutoring: Partnership in Learning, 16(3), 328-345. https://doi.org/10.1080/13611260802231708

Hayes, D. (1999). Decisions, decisions, decisions: The process of 'getting beter at teaching'. Teacher Development, 3(3), 341-354. https://doi.org/10.1080/13664539900200090

Hobson, J. A., Ashby, P., Malderez, A., \& Tomlinson, P. (2009). Mentoring beginning teachers: What we know and what we don't. Teaching and Teacher Education, 25, 207-216. https://doi.org/10.1016/j.tate.2008.09.001

Ilın, G. (2014). Practicum from the ELT student-teachers' eye: Expectations and gains. International Journal of Language Academy, 2(1), 191-207. https://doi.org/10.18033/ijla.38

İnceçay, G., \& Keşli, D. Y. (2012). Classroom management, self-efficacy and readiness of Turkish pre-service English teachers. ELT Research Journal, 1(3), 189-198. Retrieved, June 8, 2014 from http://www.ulead.org.tr/journal

Kagan, D. M. (1992). Professional growth among preservice and beginning teachers. Review of Educational Research, 62(2), 129-169. https://doi.org/10.3102/00346543062002129

Kiely, R., \& Askham, J. (2012). Furnished imagination: The impact of preservice teacher training on early career work in TESOL. TESOL Quarterly, 46(3), 496-518. https://doi.org/10.1002/tesq.39

Korth, B. B., Erickson, L., Hall, K. M., \& Martin, G. (2006). Defining 'teacher educator' through the eyes of classroom teachers. Paper presented at the meeting of the National Network for Educational Renewal, Cincinnati, OH. Retrieved from http://files.eric.ed.gov/fulltext/EJ862761.pdf

Lim, F. V., O'Halloran, K. L., \& Podlasov, A. (2012). Spatial pedagogy: Mapping meanings in the use of classroom space. Cambridge Journal of Education, 42(2), 235-251. https://doi.org/10.1080/0305764X.2012.676629

Macias, D. F., \& Sanchez, J. A. (2015). Classroom management: A persistent challenge for pre-service foreign language teachers. PROFILE, 17(2), 81-99. https://doi.org/10.15446/profile.v17n2.43641

Marshall, K. (2005). It's time to rethink teacher supervision and evaluation. Phi Delta Kappan, 86(10), 727-735. https://doi.org/10.1177/003172170508601004 
Merç, A., \& Subaş1, G. (2015). Classroom management problems and coping strategies of Turkish student EFL teachers. Turkish Online Journal of Qualitative Inquiry, 6(1), 39-71. https://doi.org/10.17569/tojqi.41736

Personn, J., \& Yiğitoğlu, N. (2015). Connecting in-service teacher education programs to classroom teaching: A case study of two novice teachers. Educational Research Association the International Journal of Research in Teacher Education, 6(2), 38-56.

Ragawanti, D. T. (2015). Cultivating pre-service teachers' classroom management skills through teaching practicum: A reflective practice. TEFLIN Journal, 25(1), 117-128. https://doi.org/10.15639/teflinjournal.v26i1/117-128

Reupert, A., \& Woodcock, S. (2010). Success and near misses: Pre-service teachers' use, confidence, and success in various classroom management strategies. Teaching and Teacher Education, 26, 1261-1268. https://doi.org/10.1016/j.tate.2010.03.003

Sarıçoban, A. (2016). Foreign language teaching practicum beliefs of student teachers. Journal of Language and Linguistic Studies, 12(1), 166-176.

Schnall, S., Witt, J. K., Augustyn, J., Stefanucci, J., Proffitt, D. R., \& Clore, G. L. (2005). Invasion of personal space influences perception of spatial layout [Abstract]. Journal of Vision, 5(8), 198, 198a. https://doi.org/10.1167/5.8.198

Scrivener, J. (2005). Learning teaching. Oxford: Macmillan Education.

Tawney, J. W., \& Gast, L. D. (1984). Single Subject Research in Special Education. Ohio: Merill.

Tsui, A. B. M. (2003). Understanding Expertise in Teaching: Case studies of second language teachers. Cambridge: Cambridge University Press. https://doi.org/10.1017/CBO9781139524698

Ünal, Z., \& Ünal, A. (2012). The impact of years of teaching experience on the classroom management approaches of elementary school teachers. International Journal of Instruction, 5(2), 41-60.

Waring, H. Z., Reddington, E., \& Tadic, N. (2016). Responding artfully to student-initiated departures in the adult ESL classroom. Linguistics and Education, 33, 28-39. DOI: 10.1016/j.linged.2015.12.0001

Wolff, C. E., Bogert, N. Jarodzka, H., \& Boshuizen, H. P. A. (2015). Keeping an eye on learning: Differences between expert and novice teachers' representations of classroom management events. Journal of Teacher Education, 66(1), 68-85. https://doi.org/10.1177/0022487114549810

Wright, T. (2005). Classroom Management in Language Education. New York: Palgrave Macmillan. https://doi.org/10.1057/9780230514188 
Appendix A: Transcription conventions for the extracts

\begin{tabular}{ll}
\hline T & Teacher (in-service) \\
TR & Trainee (pre-service) \\
S & Student \\
SS & Several students responding simultaneously \\
$(($ double parantheses)) & An observed action, or extra information about the manner of the speaker \\
$\{$ brackets $\}$ & Original words are replaced with an explanation \\
$()$. & Noticeable pause \\
(h) & Chuckle or laughter \\
comma, & Fall-rise tone indicating continuity \\
Full stop. & Fall tone indicating completion of the utterance \\
Question mark? & High rise tone or rise tone indicating surprise or question \\
Dash- & Utterance which ends abruptly due to interruption or self-correction \\
shh & Sound which has a meaning of invitation to silence \\
italics & Turkish utterances which are translated to English by the researcher \\
\hline
\end{tabular}

\section{Appendix B: The coding Scheme Based on Scrievener (2005)}

The appropriate part of the data is highlighted and an explanation is added including the appropriate code (written in bold). If required, a short explanation or a keyword (like underlined below) is added next to the code. For example ("1A student" means the teacher changed some students" seats; "1A desk" means the teacher got desk(s) pulled to change their places)

1. Grouping and Seating: Forming groupings; arranging and re-arranging seating; deciding where you will stand or sit; reforming class as a whole group after activities.

1A: is coded once for each time the teacher changes a student's seat or place of a desk

1B: is coded once for each time the teacher says/does to control the light, heat, cleanliness, visibility, audibility, orderliness, artefacts

1C: is coded once for each time the teacher changes his/her position in the class to teacher's desk, board, charts, student's desk, etc.

2. Activities: Sequencing activities; setting up activities; giving instructions; monitoring activities; timing activities and the lesson as a whole; bringing the activities to an end

2D: is coded once each time an activity type is changed to listen, read-aloud, question-answer drill, pair work, group work, solo work, repetition drill, sequence (talking to a student about a topic more than one turn), class question, book exercise

2E: is coded once each time activity is finished by saying new activity, signposting, checking time, negotiating the next activity, abrupt passing or finishing

2F: is coded once each time a teacher gives an instruction

2G: is coded each time the teacher makes a move to amend problems

3. Authority: Gathering and holding attention; deciding who does what; establishing or relinquishing authority as appropriate; getting someone do something

3H: is coded once each time a teacher says/does something to gather attention (e.g. formulaic chunk, warn by name; joke)

3I: is coded once each time a teacher warns a student off-task, praises a student on-task, reminds the rules of the activity

3J: is coded whenever a teacher nominates a student to do an exercise, to answer a question or to help

3K: is coded whenever a student gets permission from the teacher to do something

4. Critical Moments: Starting the lesson; dealing with unexpected problems, maintaining appropriate discipline, finishing the lesson 
4L: is coded when the teacher starts a lesson by signposting, greeting, small chat, revising, announcing the topic, and just starting

4M: is coded when the teacher does daily work such as attendance, announcements, on duty students, etc

$\mathbf{4 N}$ : is coded once for each time a teacher finishes a lesson by signposting or/and giving homework

4O: is coded once for each time an unexpected event happens (e.g. a visitor knocks on the door, electric shuts down, etc)

5. Tools and Techniques: using the board and other classroom equipment or aids; using gestures to help clarity of instructions and explanations; speaking clearly at an appropriate volume and speed, use of silence, grading complexity of language, grading quantity of language

5P: is coded once for each time the teacher writes something on the board. It can be a word, a sentence or a whole exercise.

5Q: is coded once for each time a teacher turns to a slide, wall chart, flipchart, book, worksheet

5R: is coded for each time a noticeable change in volume or speed of teacher's speech happened and the classroom management aim can be attributed to it

5S: is coded for each time the teacher keeps silent until students behave

5T: is coded for each time a noticeable change in the teacher's language can be attributed to classroom management purposes (e.g. gestures are used, simple language is deliberately used, Turkish is used deliberately, repetition is used, etc)

6. Working with people: Spreading your attention evenly and appropriately, using intuition to gauge what students are feeling, eliciting honest feedback from students, really listening to students.

$\mathbf{6 U}$ : is coded whenever a student initiates a new topic. The teacher can answer it or ignore it.

$\mathbf{6 V}$ : is coded whenever a teacher reflects loudly about the work of the day or the performance of the students (you must be hungry by now, etc)

6W: is coded whenever a teacher gives general feedback on class or student performance (e.g. you are sleeping today)

6Y: is coded whenever a teacher refers to the class history (e.g. yesterday's exam)

6Z: is coded for each student to whom the teacher is providing individual help. The student can ask the teacher for help, or the teacher can visit the student's desk to monitor and then decides to help.

\section{Copyrights}

Copyright for this article is retained by the author(s), with first publication rights granted to the journal.

This is an open-access article distributed under the terms and conditions of the Creative Commons Attribution license which permits unrestricted use, distribution, and reproduction in any medium, provided the original work is properly cited. 